\title{
RIQUEZA E ETNOBOTÂNICA DE PALMEIRAS NO TERRITÓRIO INDÍGENA KRAHÔ, TOCANTINS, BRASIL
}

\author{
André Rosalvo Terra Nascimento \\ Eng. Florestal, Dr., Instituto de Biologia, UFU, Uberlândia, MG, Brasil - arnterra@gmail.com \\ Recebido para publicação: 21/07/2008 - Aceito para publicação: 27/05/2009
}

\begin{abstract}
Resumo
Este trabalho objetiva caracterizar a comunidade de palmeiras e seu potencial de utilização em doze aldeias no território Krahô, um grande remanescente de cerrado, localizado no nordeste do estado do Tocantins, Brasil. Foram percorridas as principais fitofisionomias presentes cada uma das doze aldeias e registradas as espécies presentes e o potencial de utilização dessas espécies pela comunidade (alimentação, construção, medicinal, ritual, artesanato e utensílios domésticos). A riqueza de palmeiras nativas nas aldeias está representada por um total de 17 espécies e 10 gêneros, com destaque para os gêneros Attalea (quatro espécies), Syagrus (três espécies) e Astrocaryum (três espécies). A maior parte das espécies é utilizada para alimentação e construções diversas, com quase a totalidade das espécies apresentando mais de um tipo de uso. As palmeiras nativas representam um recurso vegetal imprescindível para a manutenção da qualidade de vida e dos diferentes costumes associados a esse grupo de plantas. As práticas de manejo e de conservação devem ser analisadas em um contexto etnobiológico, buscando a manutenção desse conhecimento tradicional, que está sendo perdido, para as gerações futuras.

Palavras-chave: Cerrado; potencial de utilização; produtos não-madeiráveis; conservação da biodiversidade.
\end{abstract}

\begin{abstract}
Richness and ethnobotany of palms in kraho indigenous territory, Tocantins, Brazil. This paper describes palms community and its potential of use in twelve villages in the Kraho territory, a large fragment of cerrado, located at the north-eastern of the State of Tocantins, Brazil. The main phytophysiognomy had been covered each one of the twelve villages and registered the species found and the potential of use of species for the community (feeding, constructions, medicinal, ritual, handicraft and domestic utensils). The native palms richness in the villages is represented by a total of 17 species and ten genera manly for Attalea (four species) Syagrus (three species) and Astrocaryum (three species) genera. Most of the species is used for feeding and diverse constructions, with almost the totality of the species presenting more than one type of use. The native palms represent an essential vegetal resource for the maintenance of the quality of life and the different customs associates to this group of plants. Practice of management and the conservation must be analyzed in an ethnobiologic context, searching maintenance of this traditional knowledge that is being lost for the future generations.
\end{abstract}

Keywords: Cerrado; potential of use; non-timber products; biodiversity conservation.

\section{INTRODUÇÃO}

O cerrado ocupa uma área de aproximadamente 1,8 milhão de $\mathrm{km}^{2}$ (cerca de $21 \%$ do território brasileiro) e corta diagonalmente o país no sentido nordeste-sudoeste. A área central do cerrado (área "core") limita-se com quase todos os biomas, à exceção dos campos sulinos e os ecossistemas costeiros e marinhos, mas também existem encraves de cerrado na Amazônia, na caatinga e na Mata Atlântica. Tais áreas são um remanescente de um processo histórico e dinâmico de contração e expansão das áreas de cerrado e florestas, provocadas por alterações climáticas ocorridas no passado. Tais áreas são remanescentes de um processo histórico de contração e expansão das áreas de cerrado e das florestas, provocado por alterações climáticas ocorridas no passado (AGUIAR et al., 2004). 
A vegetação do bioma cerrado apresenta fisionomias que englobam formações florestais, savânicas e campestres. Em sentido fisionômico, floresta representa áreas com predominância de espécies arbóreas, onde há formação de dossel, contínuo ou descontínuo. O termo savana refere-se a áreas com árvores e arbustos espalhados sobre um estrato graminoso, sem a formação de dossel contínuo. Já o termo campo designa áreas com predomínio de espécies herbáceas e algumas arbustivas, faltando árvores na paisagem. Entre as formações savânicas, merece destaque a denominada palmeiral, caracterizada pela presença marcante de uma espécie de palmeira arbórea. No bioma cerrado, podem ser encontrados diferentes subtipos de palmeirais, que variam em estrutura de acordo com a espécie dominante. Na área core do bioma cerrado, são encontrados palmeirais de Acrocomia aculeta (Jacq.) Lodd. ex Mart. (macaubal), Attalea speciosa Mart. ex Spreng. (babaçual) e Mauritia flexuosa L. (buritizal), entre outros (RIBEIRO; WALTER, 1998).

A flora de palmeiras do Brasil é muito rica, com estimativas variando de 221 (HENDERSON et al., 1995) até 387 espécies (GLASSMAN, 1972), estando representadas por um total de 39 gêneros. Embora muitas espécies habitem áreas florestais, somente um quarto desses gêneros compreende espécies que ocorrem em outros tipos de vegetação (JOHNSON, 1996). Para o bioma cerrado, na extensiva compilação efetuada por Mendonça et al. (1998), é citado um total de doze gêneros e 37 espécies para a família, com uma maior representatividade para os gêneros Syagrus (14 espécies), Attalea (seis espécies) e Butia (quatro espécies), somando, somente estes três gêneros, 64\% do total das espécies registradas para o bioma. Os remanescentes de cerrado (nas suas distintas fitofisionomias) localizados no estado do Tocantins (e norte do estado de Goiás) e áreas adjacentes são desconhecidos e praticamente não foram objeto de estudos publicados. Esses locais apresentam um importante centro de diversidade do bioma, devido a esses remanescentes estarem localizados em áreas de contato com a Floresta Amazônia e suas comunidades relacionadas com os remanescentes do estado do Mato Grosso (CASTRO et al., 1999).

Uma das áreas da etnobiologia (etnobotânica, etnofarmacologia, etnozoologia, etnogeologia, etnopedologia etc. sensu POSEY, 1987), a etnoecologia, em particular pode contribuir de maneira expressiva para o estudo do uso e do manejo de florestas tropicais e das formações savânicas pelas populações indígenas. A dependência dessas comunidades humanas a esses ecossistemas, com as formações secundárias de florestas tropicais e savânicas (nas suas distintas fisionomias), é bem maior do que se supunha anteriormente. Atualmente, são considerados como ecossistemas potencialmente produtivos, embora as técnicas para o seu aproveitamento racional ainda não estejam amadurecidas (POSEY, 1987).

A etnia krahô habita uma área de 320 mil hectares de extensão, cobertos em sua maioria pelas diversas fitofisionomias do bioma cerrado. Entre os recursos vegetais utilizados pelos krahôs, as palmeiras têm um papel destacado, pela sua variedade de usos e grande importância cultural nas aldeias. $\mathrm{O}$ conhecimento associado às palmeiras, além de sua importância cultural, deve ser implementado em programas de manejo e conservação de recursos genéticos, enfatizando o seu potencial de utilização no extenso território dessa etnia (NASCIMENTO et al., 2001). O povo krahô é habitante imemorial do cerrado do Planalto Central Brasileiro, ocupando um extenso território nos municípios de Itacajá e Goiatins, no estado do Tocantins. Tradicionalmente caçador, coletor e seminômade, ele passa por uma longa adaptação a um regime de vida gregário, com atividades de subsistência centradas na agricultura. $\mathrm{O}$ repatriamento de materiais genéticos deflagrou um processo, altamente positivo, de recuperação cultural e material, ocasionando um aumento da autoestima e da oferta de alimentos nesse povo. De uma etnia considerada "inviável" pelos órgãos governamentais, os krahôs passaram a ser respeitados como um povo detentor de cultura própria e importante para a humanidade (SCHIAVINI, 2000).

$\mathrm{O}$ objetivo deste estudo foi caracterizar a comunidade de palmeiras nativas em doze aldeias krahô e também descrever o potencial de utilização das espécies nessas aldeias, com vistas à conservação desse grupo de plantas e a posterior manutenção desse importante conhecimento tradicional para essa etnia no estado do Tocantins, Brasil.

\section{MATERIAL E MÉTODOS}

\section{Caracterização do território Krahô \\ Localização}

O território Krahô abrange uma área de 320.000 hectares no nordeste do estado do Tocantins, Brasil, compreendendo terras dos municípios de Itacajá e Goiatins, entre as latitudes de $07^{\circ} 50^{\prime}$ a $08^{\circ} 50^{\prime} \mathrm{S}$ e longitudes de $47^{\circ} 05^{\prime}$ a $47^{\circ} 50^{\prime} \mathrm{W}$ (Figura 1). A área localiza-se entre os rios Manuel Alves Grande e 
Manuel Alves Pequeno, afluentes da direita do rio Tocantins. É considerada uma das maiores áreas contínuas de cerrado existentes no Brasil (MOREIRA et al., 2001).

Vegetação

Ocupando a área core do bioma cerrado, o território Krahô é dominado por tipos fitofisionômicos característicos desse bioma, como campo limpo, campo sujo, veredas, cerrado stricto sensu e formações florestais como florestas de galeria e florestas estacionais (EITEN, 1975, 1994; VELOSO et al., 1991).

Solos

Segundo SEPLAN (1999), o território Krahô está situado na bacia sedimentar do rio Parnaíba, apresentando algumas manchas de cobertura cenozoica, referindo-se às coberturas detrito-lateríticas e aluvionares. Ocorre a predominância de Cambissolos, areias quartzosas, solos litólicos e podzólicos. A maior parte do território possui solos com potencial forte a muito forte de erodibilidade.

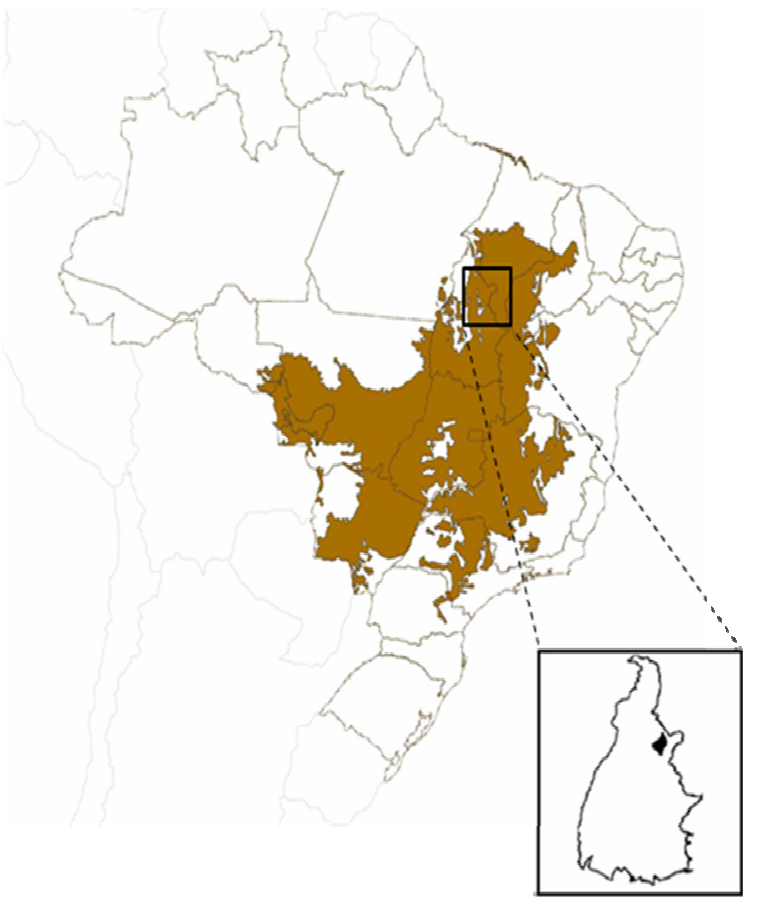

Figura 1. Distribuição do bioma cerrado (Fonte: WWF, modificado) e localização da área de estudo no Brasil (quadrado no mapa) e no estado do Tocantins (preto em detalhe).

Figure 1. Distribution of cerrado biome (Source: WWF, modified) and localization of area at this study in Brazil (squared in the map) and in Tocantins state (black in detail).

Clima

A região está sob a dominância, segundo dados das estações meteorológicas do Instituto Nacional de Meteorologia (INMET), do clima C2wA`a` (úmido subúmido com moderada deficiência hídrica) e do clima B1wA`a` (úmido com moderada deficiência hídrica). A precipitação média anual segundo o INMET está situada entre 1600 e $1700 \mathrm{~mm}$, sendo a temperatura média anual em torno de $28^{\circ} \mathrm{C}$. Ainda segundo SEPLAN (1999), o clima úmido predominante na região apresenta pequena ou nula deficiência hídrica, evapotranspiração potencial média anual de $1.700 \mathrm{~mm}$, distribuindo-se no verão em torno de $500 \mathrm{~mm}$ ao longo dos três meses consecutivos com temperatura mais elevada.

\section{Método de levantamento florístico e etnobotânico}

O método de desenvolvimento deste trabalho dentro do território Krahô seguiu o procedimento de levantamento participativo adotado pelo projeto "Etnobiologia, conservação de recursos genéticos e bem- 
estar alimentar em comunidades tradicionais", desenvolvido pela Embrapa Recursos Genéticos e Biotecnologia (CENARGEN) em conjunto com outras instituições de pesquisa. Foi realizada uma discussão sobre a realização do levantamento de palmeiras nas aldeias krahô, em reunião na Associação União das Aldeias Krahô - Kapey. Em cada aldeia visitada, foi realizada uma reunião inicial, com a presença dos caciques e da comunidade, em que foram discutidos os objetivos e as premissas do trabalho. Foi também abordada, nessa reunião, a necessidade da pesquisa ser acompanhada por uma pessoa da aldeia que detivesse conhecimento relacionado à taxonomia krahô, ambiente de ocorrência e potencial de utilização.

Foi calculado o valor de equitabilidade de uso $\left(\mathrm{UE}_{\mathrm{s}}\right)$ para todas as espécies de palmeiras. Esse índice mede como diferentes usos contribuem para o uso total de uma espécie, independentemente do número de categorias de uso. Os valores variam entre 0 e 1, sendo calculado da seguinte forma (SILVA et al. 2008):

$$
\mathrm{UE}_{\mathrm{s}}=\mathrm{UD}_{\mathrm{s}} / \mathrm{UD}_{\mathrm{Max}}
$$

Em que: $\mathrm{UD}_{\mathrm{Max}}=$ valor de diversidade de uso máximo possível para uma espécie s com uso em um dado número de categorias. $\mathrm{O} \mathrm{UE}_{\mathrm{s}}$ é calculado pelo valor da diversidade de uso $\left(\mathrm{UD}_{\mathrm{s}}\right)$ dividido pelo valor máximo do referido índice.

Para a coleta e levantamento florístico desse grupo de plantas, foram percorridas doze aldeias (Aldeia Nova, Pedra Branca, Cachoeira, Forno Velho, Galheiro, Morro do Boi, Rio Vermelho, Santa Cruz, Bacuri, Pedra Furada, Manoel Alves, Serra Grande e Kapey). Foi utilizado para o levantamento da comunidade de palmeiras o método de levantamento rápido por caminhamento (ver FILGUEIRAS et al., 1994; ERWIN, 2003; MARENZI; RODERJAN, 2005) ligeiramente modificado. Em cada aldeia, foram percorridas as principais fitofisionomias, sendo anotadas as espécies de palmeiras presentes em cada uma delas e a riqueza total de espécies por aldeia, resultante do somatório das espécies de todas as fitofisionomias.

A identificação, quando não possível no campo, foi realizada por meio de comparação do material coletado com as exsicatas nos herbários regionais de referência para o cerrado (CEN, HUB e IBGE) e também por consulta a bibliografia especializada para esse grupo de plantas (UHL; DRANSFIELD, 1987; KHAN; GRANVILLE, 1992; HENDERSON et al., 1995; GLASSMAN, 1999; KAHN, 2001; BERNAL; GALEANO, 2006). Os nomes científicos e os gêneros foram conferidos quanto à grafia correta e os autores no site do Missouri Botanical Garden (www. mobot.org.).

Com base na listagem de espécies encontrada em cada uma das doze aldeias, foi analisada a riqueza da comunidade de palmeiras, utilizando-se um estimador de riqueza de espécies de primeira ordem Jackknife 1. Esse índice encontra-se disponível no software EstimateS 8.0 (COLWELL, 2006) e é descrito da seguinte forma:

$$
\mathrm{S}_{\text {Jack } 1}=\mathrm{S}_{\mathrm{obs}}+\mathrm{Q}_{1}\left[\frac{m-1}{m}\right]
$$

Em que: $\mathrm{Q}_{1}$ é o número de espécies encontradas somente em uma única amostra, e $\mathrm{m}$ é o número de amostras.

O uso de estimadores de riqueza é uma técnica usual para se obter a estimativa do número de itens (espécies, por exemplo) que poderiam ainda ter sido computados num determinado local, sem levar em conta necessariamente a densidade dos indivíduos, ou número de citações por espécie. A técnica Jackknife é um procedimento utilizado para reduzir a subestimativa do verdadeiro número de espécies em uma amostragem, fundamentando-se no número de itens representados na amostra. A primeira ordem do estimador Jackknife é baseada na presença de "uniques" - espécies ou citações de espécies, presentes em uma única unidade amostral. Esse procedimento expressa uma estimativa da riqueza calculada a partir da aleatorização da posição das amostras. Assim, são calculados os valores médios de riqueza para combinações aleatórias de uma, duas, três amostras e assim sucessivamente, até completar o valor total de amostras (COLWELL; CODDINGTON, 1994; PERONI et al., 2008). 


\section{RESULTADOS E DISCUSSÃO}

\section{Padrões de riqueza de espécies e importância ecológica}

A comunidade de palmeiras nas doze aldeias está representada por 17 espécies nativas, distribuídas em dez gêneros, sendo os mais representativos Attalea, com quatro espécies, e Syagrus e Astrocaryum, com três espécies cada um (Tabela 1). A maior parte das espécies apresentou hábito arbóreo (Figura 2), com alturas acima de 8 metros $(64,7 \%)$, seguidas das espécies com caule subterrâneo $(23,6 \%)$. Nas fisionomias savânicas e áreas abertas, as espécies com caules subterrâneos parecem predominar, e nas áreas com fisionomias florestais o hábito arbóreo é mais frequente.

Tabela 1. Espécies de palmeiras nativas encontradas no território Krahô, com seus respectivos nomes vulgares e krahô. Região nordeste do estado do Tocantins, Brasil.

Table 1. Species of native palms found in Krahô territory, with their respective common and krahô names. Northeast region of Tocantins state, Brazil.

\begin{tabular}{|c|c|c|c|}
\hline $\begin{array}{c}\text { Espécies nativas } \\
\end{array}$ & $\mathbf{U E}_{\mathrm{s}}$ & Nome vulgar & Nome krahô \\
\hline 1. Gênero Acrocomia Mart. & & & \\
\hline $\begin{array}{l}\text { Acrocomia aculeata (Jacq.) Lodd. ex Mart. } \\
\text { 2. Gênero Allagoptera Nees }\end{array}$ & 0,33 & Macaúba & Roy rak \\
\hline Allagoptera leucocalyx (Mart.) Kuntze & 0,33 & Ariri & Kretan ré \\
\hline 3. Gênero Astrocaryum G. Mey. & & & \\
\hline Astrocaryum campestre Mart. & 0,33 & Tucum-rasteiro & Ro \\
\hline Astrocaryum vulgare Mart. & 0,33 & Tucum-da-mata & Roy ti \\
\hline Astrocaryum jauari Mart. & 0,33 & Tucum & Roy ti \\
\hline 4. Gênero Attalea Kunth & & & \\
\hline Attalea geraensis Barb. Rodr. & 0,33 & Piaçava & Ror peho \\
\hline Attalea maripa (Aubl.) Mart. & 0,50 & Inajá & Awara \\
\hline Attalea speciosa Mart. ex. Spreng. & 0,33 & Babaçú & Ro tere \\
\hline $\begin{array}{l}\text { Attalea sp. } \\
\text { 5. Gênero Euterpe Mart. }\end{array}$ & 0,16 & Coco-cunhã & Karonte \\
\hline $\begin{array}{l}\text { Euterpe edulis Mart. } \\
6 \text { Gênero Geonoma Willd. }\end{array}$ & 0,33 & Juçara & Ter ti \\
\hline $\begin{array}{l}\text { Geonoma sp. } \\
\text { 7. Gênero Mauritia L. }\end{array}$ & 0,33 & Guaricana & Terere \\
\hline $\begin{array}{l}\text { Mauritia flexuosa } \mathrm{L} \text {. } \\
\text { 8. Gênero Mauritiella Burret }\end{array}$ & 0,66 & Buriti & Krow \\
\hline $\begin{array}{l}\text { Mauritiella aculeata (Kunth.) Burret. } \\
\text { 9. Gênero Oenocarpus Mart. }\end{array}$ & 0,5 & Buritirana & Krawrore \\
\hline $\begin{array}{l}\text { Oenocarpus distichus Mart. } \\
\text { 10. Gênero Syagrus Mart. }\end{array}$ & 0,66 & Bacaba-de-leque & Kapir \\
\hline Syagrus cocoides Mart. & 0,50 & Pati-grande & Hõ ti \\
\hline Syagrus comosa (Mart.) Mart. & 0,50 & Catolé & Hõ thré \\
\hline Syagrus sp. & 0,33 & Pati & Hõ ti \\
\hline
\end{tabular}

$\mathrm{UE}_{\mathrm{s}}$ : Valor de equitabilidade de uso.

Estudando as comunidades de palmeiras das florestas tropicais da bacia do Tocantins, Kahn (1986) descreve uma riqueza de 21 espécies, compreendendo oito palmeiras arbóreas, doze de sub-bosque e uma lianescente. Entre as espécies arbóreas, destacam-se Attalea regia (Mart.) W. Boer, Euterpe oleracea Mart., Oenocarpus bacaba Mart., Oenocarpus distichus Mart. e Attalea speciosa Mart. ex Spreng. Entre as espécies de sub-bosque, estão Astrocaryum munbaca Mart., Bactris humilis (Wallace) Burret e Geonoma deversa (Poit.) Kunth., todas com elevada densidade de indivíduos.

A estimativa da riqueza das espécies nas doze aldeias (Figura 3) mostra que a maior parte das espécies da comunidade de palmeiras possivelmente foi amostrada, e as estimativas contidas neste trabalho, embora incipientes, podem ser consideradas dentro dos padrões encontrados em remanescentes de cerrado no Brasil central. O número de espécies contidas neste trabalho representa cerca de $46 \%$ das 
espécies citadas por Mendonça et al. (1998) e 41\% das espécies mencionadas por Castro et al. (1999) para todo o bioma cerrado. Essas observações chamam a atenção para a expressiva diversidade de espécies da comunidade de palmeiras no território Krahô e reforçam as afirmações de Ratter et al. (2003) sobre a importância desses remanescentes situados no estado do Tocantins, sendo reconhecidos como um grupo florístico distinto dentro do bioma cerrado.

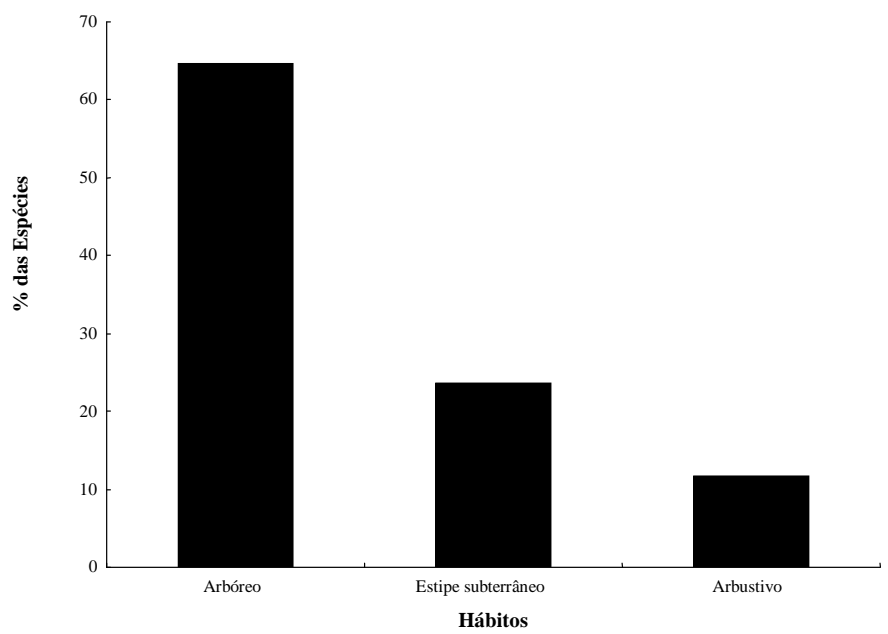

Figura 2. Distribuição do número de espécies de palmeiras por tipo de hábito, em doze aldeias no território Krahô, nordeste do estado do Tocantins, Brasil.

Figure 2. Distribution of the number of palms species by type of habit, in twelve villages in Krahô territory, northeast region of Tocantins state, Brazil.

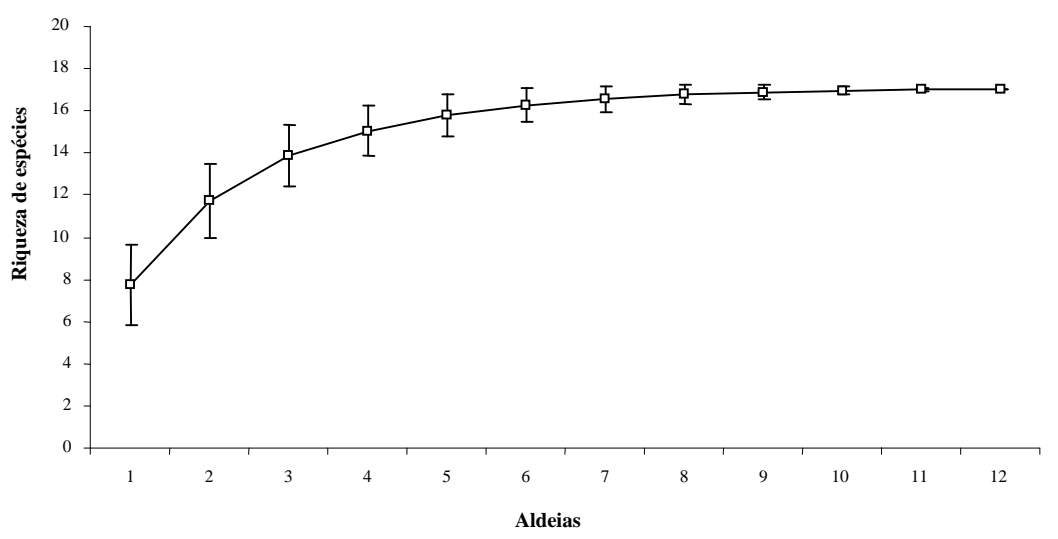

Figura 3. Estimativa da riqueza de espécies de palmeiras usando o estimador Jackkniffe de primeira ordem em doze aldeias no território Krahô, nordeste do estado do Tocantins, Brasil.

Figure 3. Estimate of palm species richness of using the first order Jackkniffe estimator in twelve villages in Krahô territory, northeast region of Tocantins state, Brazil.

Muitas das espécies de palmeiras nativas são de enorme importância econômica para a produção de óleos, como fornecedoras de matéria-prima para cobertura de casas e confecção de artesanato e de utensílios. No meio rural, muitas palmeiras são utilizadas como alimento, e sob o ponto de vista ecológico são de suma importância para o homem e para a fauna. Na realidade, nenhum levantamento sistematizado foi realizado para esse grupo de plantas em todo o bioma cerrado (MARTINS, 2005). Dessa forma, a diversidade de espécies de palmeiras no bioma cerrado encontra-se subamostrada, com a maior parte dos levantamentos de vegetação não considerando esse componente. Assim, as estimativas de riqueza e 
diversidade podem ser inferiores à realidade desse extenso bioma no Brasil, uma vez que muitas localidades sequer foram amostradas devidamente.

Um dos poucos levantamentos sistematizados, efetuado por Martins; Filgueiras (2006), reconheceu 14 espécies e oito gêneros nativos para a região do Distrito Federal, na porção central do bioma, com uma maior riqueza para os gêneros Syagrus (cinco espécies) e Attalea (três espécies). Mesmo com o parco conhecimento sobre a flora de palmeiras, pode-se inferir que esses dois gêneros, que estão bem representados nos trabalhos existentes para o bioma, sejam importantes na diversidade desse grupo de plantas. A necessidade de levantamentos sistematizados em um maior número de localidades, juntamente com revisões detalhadas enfatizando esse importante grupo de plantas, permitirá uma visão mais aprofundada sobre as palmeiras nativas no bioma cerrado.

\section{Aspectos etnobotânicos e recursos genéticos}

O suporte ambiental representado por esse grupo de plantas pode ser evidenciado pela sua expressiva utilização na alimentação, principalmente na época de menor disponibilidade de recursos, entre as safras nas roças e quintais, tornando-se ainda mais importante durante a estação seca. Segundo Barbosa; Schmitz (1998), na estação chuvosa o sistema biogeográfico do cerrado fornece uma grande variedade de recursos, representada por frutos, insetos comestíveis, mel silvestre, moluscos, mamíferos, aves e pequenos répteis. Tais recursos se distribuem pelas fisionomias de campo, cerradão e mata de galeria, possibilitando cada um o exercício de atividades de coleta e de caça. Essas atividades exigem uma divisão de trabalho por sexo e faixa etária, e, fundamentalmente, a atividade da caça exige a divisão em grupos menores de índios.

O potencial de utilização das espécies de palmeiras pode ser visualizado na figura 4. Um aspecto a ser considerado é que a maior parte das espécies apresentou mais de uma categoria de uso, com a maior parte das espécies apresentando entre dois e quatro tipos de usos nas aldeias e um pequeno número apresentando um único tipo de uso. Entre as espécies encontradas $(\mathrm{N}=17)$ nas comunidades visitadas, Mauritia flexuosa (buriti), Oenocarpus distichus (bacaba) e Attalea maripa apresentaram um maior potencial de utilização, com quatro tipos de uso cada.

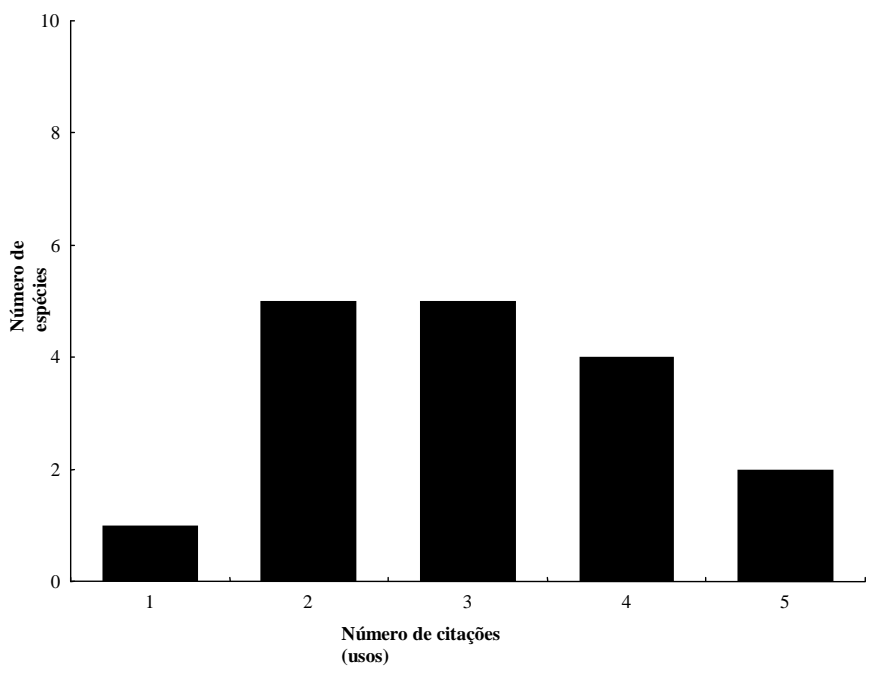

Figura 4. Número de citações (usos) das 17 espécies de palmeiras, em doze aldeias no território Krahô, nordeste do estado do Tocantins, Brasil.

Figure 4. Citation number (uses) of the 17 palms species, in twelve villages in Krahô territory, northeast of the state of the Tocantins, Brazil.

Foram observados seis diferentes tipos de usos: alimentação e bebidas, construção, medicinal, ritual, artesanato e utensílios domésticos. A maior parte das espécies de palmeiras nativas é utilizada na alimentação e na forma de bebidas (36,7\%). Em segundo lugar, vêm as construções diversas $(23,3 \%)$, com os estipes de algumas espécies (p. ex., gêneros Euterpe, Mauritia) sendo utilizados na construção de 
pontes rústicas e como material para caibros nas casas. A utilização de folhas para cobertura de casas (p. ex., gêneros Syagrus, Attalea e Mauritia) é uma atividade recorrente e deve ser analisada em uma abordagem que considere as populações naturais e os aspectos da sustentabilidade de produção desse recurso vegetal. Com relação ao valor de equitabilidade de uso $\left(\mathrm{UE}_{\mathrm{s}}\right)$, as espécies Mauritia flexuosa $\left(\mathrm{UE}_{\mathrm{s}}=0,66\right)$, Oenocarpus distichus $\left(\mathrm{UE}_{\mathrm{s}}=0,66\right)$ e Mauritiella aculeata $\left(\mathrm{UE}_{\mathrm{s}}=0,50\right)$ apresentaram os maiores valores calculados (Tabela 1) e destacam-se sobre as demais espécies. As duas primeiras espécies, além de sua importância na alimentação (na forma de bebidas - "vinhos") destacam-se como as duas espécies de palmeiras utilizadas em rituais.

A maioria das palmeiras nativas usadas como alimento pelos povos indígenas possui mesocarpo com amido e óleo em diferentes proporções. Todas as palmeiras mencionadas como oleaginosas também são usadas como alimentos, devido à presença de amido, proteínas e vitaminas, além do óleo. As palmeiras usadas como alimentos são preparadas como sucos (geralmente chamados de 'vinho' na Amazônia), cozidas (pupunha) ou até frescas (tucumã). Tradicionalmente, as que apresentam maior conteúdo de amido são usadas para fermentação, com destaque para a pupunha (CLEMENT et al., 2005). Esse tipo de uso é aplicado pelos krahôs para Mauritia flexuosa, Oenocarpus distichus e espécies do gênero Attalea spp., com destaque para o óleo extraído do babaçu (A. speciosa), utilizado como óleo vegetal com múltiplas aplicações.

Um outro tipo de uso para espécies de palmeiras reportado na literatura (FRAUSIN et al., 2008) é a sua utilização para artesanato, usando-se diferentes partes da planta, com destaque para as sementes, folhas e estipe. Nesse sentido, Frausin et al. (2008) mencionam a utilização de seis espécies de palmeiras nativas pelos índios Emberá-Katío na Colômbia, com as espécies Attalea maripa e Euterpe sp. apresentando a maior diversificação de usos para diferentes tipos de artesanato. Entre os krahôs, as espécies Attalea maripa, Mauritia flexuosa, Euterpe edulis e espécies do gênero Astrocaryum spp. são utilizadas com essa finalidade e comercializadas localmente (nas aldeias) e nas cidades próximas ao território.

Espécies do gênero Astrocaryum spp. são mencionadas na literatura como uma das fibras vegetais mais resistentes que existem (COOMES, 2004), sendo utilizadas pelos krahôs na confecção de redes e esteiras de grande durabilidade natural. Espécies importantes para comunidades ribeirinhas e populações indígenas da Amazônia e adjacências, como Astrocaryum aculeatum Meyer, que apresenta grande produção de frutos e notável variabilidade no tamanho deles, características desejáveis no melhoramento genético, carecem de coleções in situ (MOUSSA; KHAN, 1997).

A extração de indivíduos e a coleta (de folhas, frutos e estipes) sem preocupação com o manejo e a conservação das populações naturais devem ser reavaliadas, visando a posterior manutenção dessas populações naturais no território dessa etnia. Indícios de superexploração dos recursos já são notados em algumas espécies e podem comprometer as populações dessas espécies nesses ecossistemas.

Estudando três comunidades rurais da caatinga na região Nordeste do Brasil, Lucena et al. (2007) mencionam que a maior parte das espécies estudadas pelos autores $(67 \%)$ apresenta mais de um tipo de uso ( 2 a 3 tipos de uso), indicando uma forte tendência das espécies da caatinga de apresentar uma multiplicidade de utilização nas comunidades rurais estudadas. Entre os recursos naturais utilizados pelas comunidades, algumas espécies de plantas apresentam severos níveis de exploração e/ou alta pressão de uso, como resultado da sua importância local e disponibilidade, necessitando de um maior envolvimento das comunidades locais no manejo e na conservação desses recursos.

Um aspecto relevante sobre as práticas agrícolas da etnia krahô é que grande parte do território é constituído de solos arenosos e de baixa fertilidade, afetando os níveis de produtividade e acarretando o abandono das áreas. Devido a sua importância no hábito alimentar dessa comunidade indígena, a mandioca é uma espécie presente na maioria das roças, sendo cultivada em sistema de consórcio (com arroz e feijão guandu) e também em sistema denominado de cultura solteira. Durante a estação seca, os krahôs incluem espécies de palmeiras, como o buriti (Mauritia flexuosa L.), bacaba (Oenocarpus distichus Mart.) e macaúba (Acrocomia aculeata (Jacq.) Lodd. ex Mart.) (Moreira et al., 2001). Essas espécies de palmeiras poderiam ser utilizadas com sucesso em modelos de sistemas agroflorestais, como já é feito em algumas roças, onde as palmeiras são mantidas para serem utilizadas na estação seca, quando a disponibilidade de recursos nas aldeias diminui ou se torna escasso.

Os métodos para coleta de germoplasma de palmeiras nativas muitas vezes podem ser definidos, testados, aperfeiçoados e consolidados durante os trabalhos de coleta, devido à inexistência de 
metodologia aplicável à coleta de germoplasma de palmeiras. Dentro de uma família como a das palmeiras, as sementes de algumas espécies devem ser germinadas em poucos dias e manuseadas com cuidado, enquanto que outras podem suportar um ano de estocagem, permanecendo ainda viáveis. Através do intenso e extenso trabalho de coleta, caracterização e conservação do material coletado, tornase possível a seleção de um número de caracteres desejáveis em programas de melhoramento genético e a identificação de materiais promissores em diversos aspectos, como produtividade, precocidade, elevados percentuais de amêndoa, porte reduzido, adaptação a solos de baixa fertilidade e menor resistência do endocarpo, entre outros (PINHEIRO et al., 2005).

Tanto na conservação da natureza quanto na de recursos genéticos, muitos animais e plantas, relativamente desconhecidos, são casualmente protegidos. Os melhoristas podem considerar a conservação da natureza como um sistema que ajuda a proteger o germoplasma de potencial valor, mesmo que o seu valor seja ainda desconhecido ou pouco valorado (HOYT, 1992). Nesse sentido, a importância imediata deve ser dada para espécies de palmeiras com múltiplas utilizações (e pouco valoradas) e que possam ser incorporadas em sistemas mistos, visando aumentar a diversidade de elementos e diversificar a produtividade usando-se esse grupo de plantas como elementos de ciclo mais longo.

\section{CONCLUSÕES}

A comunidade de palmeiras no território Krahô apresenta uma notável riqueza de espécies, as quais são utilizadas para uma gama variada de usos, destacando-se a alimentação e a construção de casas. As estratégias envolvendo o manejo e a conservação das populações naturais devem ser embasadas em programas de conservação in situ, os quais carecem com urgência de levantamentos populacionais das espécies.

As palmeiras nativas representam um recurso vegetal imprescindível para a manutenção da qualidade de vida e dos diferentes costumes associados a esse grupo de plantas. A avaliação das espécies potenciais deve ser analisada em um contexto etnobiológico, buscando-se manter esse importante conhecimento tradicional, que está sendo perdido, para as gerações futuras.

\section{AGRADECIMENTOS}

À Embrapa - Cenargen de Brasília DF e à Fundação Nacional do Índio (FUNAI), pelo apoio logístico. A Fernando Schiavini, pelas informações sobre esse grupo de plantas. Aos especialistas Francis Kahn e Renata Corrêa Martins, pelo auxílio na confirmação de algumas espécies. A Ernestino de Souza Guarino, pelas valiosas contribuições ao trabalho.

A propriedade intelectual do conhecimento tradicional referente a este trabalho está contemplada no projeto "Etnobiologia, conservação de recursos genéticos e bem-estar alimentar em comunidades tradicionais", envolvendo a Embrapa - Cenargen de Brasília DF, a Fundação Nacional do Índio (FUNAI) e a Associação Indigena Krahô - Kapey.

Este trabalho é dedicado à comunidade indígena krahô, representada pela Associação Indígena Krahô - Kapey.

\section{REFERÊNCIAS}

AGUIAR L. M. S.; MACHADO, R. B.; MARINHO-FILHO, J. A diversidade biológica do Cerrado. In: AGUIAR, L. M. S.; CAMARGO, A. J. (Eds.) Cerrado: ecologia e caracterização. Brasília, DF: EMBRAPA Cerrados, 2004. p. 17-40.

BARBOSA, A. S.; SCHMITZ, P. I. Ocupação indígena do cerrado. In: SANO, S. M.; ALMEIDA, S. P. (Eds.). Cerrado: ambiente e flora. Planaltina: EMBRAPA - CPAC, 1998. p. 4-43.

BERNAL, R.; GALEANO, G. Endangerment of Colombian Palms (Arecaceae): change over 18 years. Linnean Society. Botanical Journal, Oxford, v. 151, p. 151-163, 2006.

CASTRO, A. A. J. F.; MARTINS, F. R.; TAMASHIRO, J. Y.; SHEPHERD, G. J. How rich is the flora of Brazilian cerrados? Missouri Botanical Garden. Annals, Saint Louis, v. 86, p. 192-224, 1999. 
CLEMENT, C. R.; LLERAS PÉREZ, E.; VAN LEEUWEN, J. O potencial das palmeiras tropicais no Brasil: acertos e fracassos das últimas décadas. Agrociencia, Montevideo, v. 9, n.1-2, p. 67-71, 2005.

COOMES, O. T. Rain forest 'conservation through use'? Chambira palm fiber extraction and handicraft production in a land-constrained community, Peruvian Amazon. Biodiversity and Conservation, London, v. 13, p. 351-360, 2004.

COLWELL, R. K.; CODDINGTON, J. A. Estimating terrestrial biodiversity through extrapolation. Philosophical Transactions of the Royal Society of London, London, v. 345, p.101-118, 1994.

COLWELL, R. K. Estimates: statistical estimation of species richness and shared species for samples. Version 8. 2006. DSísponível em: 〈http://purl.org/estimates〉. Acesso em: 22/05/2009.

EITEN, G. The vegetation of the Serra do Roncador. Biotropica, Washington, DC, v. 7, n. 2, p. 112-135, 1975 .

EITEN, G. Vegetação do Cerrado. In: PINTO, M.N. (Org.). Cerrado: caracterização, ocupação e perspectivas. Brasília, DF: UnB/SEMATEC, 1994. p. 9-65.

ERWIN, J. Rapid assessment of protected area management effectiveness in four Countries. BioScience, Washington, DC, v. 53, n. 9, p. 833-841, 2003.

FILGUEIRAS, T. S.; NOGUEIRA, P. E.; BROCHADO, A. L.; GUALA II, G. F. Caminhamento - um método expedito para levantamentos florísticos qualitativos. Cadernos de Geociências (Rio de Janeiro), Rio de Janeiro, v. 12, p. 39-43, 1994.

FRAUSIN, G.; CORREA, M. A.; GONZALES, V. C. Seeds used in handicrafts manufactured by an EmberáKatío indigenous population displaced by violence in Colombia. Caldasia, Bogota, v. 30, n. 2, p. 315-123, 2008.

GLASSMAN, S. A taxonomic treatment of the palm subtribe Attaleinae (tribe Cocoeae). Urbana: University of Illinois Press, 1999.

GLASSMAN, S. A revision of B. E. Dahlgren's index of American palms. Lehre : J. Cramer, 1972.

HENDERSON, A.; GALEANO, G.; BERNAL, R. Field guide to the palms of the Americas. New Jersey: Princeton University Press, 1995. 351 p.

HOYT, E. Conservation the wild relatives of crops. Roma: IBGR/FAO. 1992. 52 p.

JOHNSON, J. (ed.) and the IUCN/SSN Palm Specialist Group. Palms: their conservation and sustained utilization. Cambridge: IUCN, 1996. 116 p.

KHAN, F.; GRANVILLE, J. J. Palms in forest ecosystems of Amazonia. Berlin: Springer-Verlag, 1992. 320 p.

KHAN, F. Les palmiers des forêts tropicales humides du bas Tocantins (Amazonie bresilienne). Revue de Ecologie: La terre et la vie, Paris, v. 41, p. 3-13, 1986.

KHAN, F. El género Astrocaryum (Palmae) en el Perú. Biota, Lima, n. 100, p. 56-73, 2001.

LUCENA, R. F. P.; ALBUQUERQUE, U. P.; MONTEIRO, J. M.; ALMEIDA, C. F. C. B. R.; FLORENTINO, A. T. N.; FERRAZ, J. S. F. Useful plants of the semi-arid northeastern region of Brazil - a look at their conservation and sustainable use. Environmental Monitoring and Assessment, Dordrecht, v. 125, p. 281-290, 2007.

MARENZI, R. C.; RODERJAN, C. V. Estrutura espacial da paisagem da morraria da Praia Vermelha (SC): subsídio à ecologia de paisagem. Floresta, Curitiba, v. 35, n. 2, p. 259-269, 2005.

MARTINS, R. C.; FILGUEIRAS, T. S. Arecaceae. In: CAVALCANTI, T. C. (Org.). Flora do Distrito

Federal, Brasil. Brasília, DF: EMBRAPA Recursos Genéticos e Biotecnologia. 2006. p. 47-82. 
MARTINS, R. C. Apa da Cafuringa: um olhar sobre as palmeiras. In: NETTO, P. B.; MECENAS, V. V.; CARDOSOS, E. S. (Eds.). Apa da Cafuringa: a última fronteira natural do DF. Brasília, DF: Secretaria do Meio Ambiente e Recursos Hídricos. 2005. p. 178-180.

MENDONÇA, R. C.; FELFILI, J. M.; WALTER, B. M. T.; SILVA JÚNIOR, M. C.; REZENDE, A. V.; FILGUEIRAS, T. S.; NOGUEIRA, P. E. Flora vascular do cerrado. In: SANO, S. M.; ALMEIDA, S. P. (Eds.). Cerrado: ambiente e flora. Planaltina: EMBRAPA - CPAC, 1998. p. 289-556.

MOREIRA, L.; REATTO, A.; ANDRADE, L. R. M.; MARTINS, E. S. Diagnóstico indígena participativo - Aldeia Pedra Branca Terra Indígena Krahô Itacajá, Tocantins. Planaltina: EMBRAPA Cerrados. 2001. 40 p. (Série Documentos, n. 40).

MOUSSA, F.; KHAN, F. Uso y potencial económico de dos palmas, Astrocaryum aculeatum Meyer y A. vulgare Martius, en la Amazonía brasileña. In: RIOS, M.; PEDERSEN, H. B. (Eds.). Uso y manejo de recursos vegetales. Quito: Abya-Yala. 1997. p. 101-116.

NASCIMENTO, A. R. T.; GUARINO, E. S.; DIAS, T. A. B.; SANTOS, A. A. Espécies de palmeiras utilizadas pelos Krahôs, uma comunidade indígena do Brasil. In: SIMPÓSIO DE RECURSOS GENÉTICOS PARA A AMÉRICA LATINA E CARIBE - SIRGEALC, 3., 2001, Londrina. Anais...Londrina: IAPAR, 2001. p. 715-716.

PERONI, N.; ARAUJO, H. F. P.; HANAZAKI, N. Métodos ecológicos na investigação etnobotânica e etnobiológica: o uso de medidas de diversidade e estimadores de riqueza. In: ALBUQUERQUE, U. P.; LUCENA, R. F. P.; CUNHA, L.V. F. C. (Eds.). Métodos e técnicas na pesquisa etnobotânica. Recife: Comunigraf, 2008. p. 199-225.

PINHEIRO, C. U. B.; FRAZÃO, J. M.; BALICK, M. J. Coleta de germoplasma de palmeiras do complexo babaçu (Orbignya e Attalea). In: WALTER, B. M. T.; CAVAlCANTI, T. B. (Eds.). Fundamentos para coleta de germoplasma vegetal. Brasília, DF: EMBRAPA Recursos Genéticos e Biotecnologia. 2005. p. 549-583.

POSEY, D. A. Manejo da floresta secundária, capoeira, campos e cerrados (Kayapó). In: RIBEIRO, B. G. (Coord.). Suma Etnológica Brasileira. Petrópolis: FINEP, 1987. p. 173-185.

RATTER, J. A.; BRIDGEWATER, S.; RIBEIRO, J. F. Analysis of floristic composition of the Brazilian Cerrado vegetation III. Comparison of wood vegetation of 376 areas. Edinburgh Journal of Botany, Cambridge, v. 60, n. 1, p. 57-109, 2003.

RIBEIRO, J. F.; WALTER, B. M. T. Fitofisionomias do bioma Cerrado. In: SANO, S. M.; ALMEIDA, S.P. (Eds.). Cerrado: ambiente e flora. Planaltina: EMBRAPA - CPAC. 1998, p. 89-166.

SCHIAVINI, F. Estudos etnobiológicos com o povo Krahò. In: Cavalcanti TB, Walter BMT (Orgs.). Tópicos atuais em Botânica. Brasília, DF: Sociedade Botânica do Brasil: EMBRAPA Recursos Genéticos e Biotecnologia. 2000. p. 278-284.

PALMAS (TO). Secretaria de Planejamento e Meio Ambiente (SEPLAN). Atlas do Tocantins: subsídios ao planejamento da gestão territorial. Secretaria do Planejamento e Meio Ambiente, Diretoria de Zoneamento Ecológico-Econômico. Palmas: Seplan, 1999, 49 p.

SILVA, A. V.; ALBUQUeRQUE, U. P.; NASCIMENTO, V. T. Técnicas para análise de dados etnobotânicos. In: ALBUQUERQUE, U. P.; LUCENA, R. F. P.; CUNHA, L.V. F. C. (Eds.). Métodos e técnicas na pesquisa etnobotânica. Recife: Comunigraf, 2008. p. 127-143.

UHL, C.; DRANSFIELD, J. Genera Palmarum. A classification of palms based on the work of Harold E. moore Jr. Lawrence: Allen, 1987. 610 p.

VELOSO, H. P.; RANGEL-FILHO, A. L. R.; LIMA, J. C. A. Classificação da vegetação Brasileira, adaptada a um sistema universal. Rio de Janeiro: IBGE. 1991. 124 p.

WORLD WILDLIFE FOUND/WWW. Biomas do Brasil Cerrado. Disponível em: <hrrp://www.wwf.org.br>. Acesso em: 22/05/2009. 
